\title{
Jacques Paviot, Les ducs de Bourgogne, la croisade et l'Orient
}

\section{Maria Colombo Timelli}

\section{(2) OpenEdition}

10 Journals

\section{Édition électronique}

URL : http://journals.openedition.org/studifrancesi/32836

DOI : $10.4000 /$ studifrancesi.32836

ISSN : 2421-5856

Éditeur

Rosenberg \& Sellier

\section{Édition imprimée}

Date de publication : 1 décembre 2005

Pagination : 617

ISSN : 0039-2944

\section{Référence électronique}

Maria Colombo Timelli, « Jacques Paviot, Les ducs de Bourgogne, la croisade et l'Orient », Studi Francesi

[En ligne], 147 (XLX | III) | 2005, mis en ligne le 30 novembre 2015, consulté le 20 avril 2021. URL : http://journals.openedition.org/studifrancesi/32836; DOI : https://doi.org/10.4000/studifrancesi. 32836

Ce document a été généré automatiquement le 20 avril 2021.

\section{(c)}

Studi Francesi è distribuita con Licenza Creative Commons Attribuzione - Non commerciale - Non opere derivate 4.0 Internazionale. 


\title{
Jacques Paviot, Les ducs de Bourgogne, la croisade et l'Orient
}

\author{
Maria Colombo Timelli
}

\section{RÉFÉRENCE}

JACQUES PAVIOT, Les ducs de Bourgogne, la croisade et l'Orient, Paris, Presses de l'Université de Paris-Sorbonne, 2003, 392 pp.

1 Cet ouvrage d'un historien spécialiste tant des projets de croisade 'tardifs' que de la cour de Bourgogne nous intéresse dans la mesure où il fait une large place (en suivant la trace des travaux 'classiques' de Georges Doutrepont, et plus récemment de Constantin Marinesco et d'Yvon Lacaze) à la littérature dite 'bourguignonne' en rapport avec l'idée et les projets de croisade élaborés au XV $\mathrm{XV}^{\mathrm{e}}$ siècle surtout sous Philippe le Bon.

2 Le plan s'articule en deux parties. La première (Les ducs de Bourgogne et la croisade, pp. 15-195) offre un cadre chronologique minutieux et bien documenté, allant de l'expédition de Nicopolis (1396) à la fin de la dynastie des ducs Valois (1477, mort de Charles le Téméraire). La deuxième section (L'Orient à la cour de Bourgogne, pp. 197-290) se veut plutôt thématique; les quatre chapitres concernent la 'librairie' ducale ( $L a$ croisade et l'Orient dans la bibliothèque des ducs de B., pp. 201-238), les relations des ducs avec les deux puissances latines de la Méditerranée orientale, Chypre et Rhodes (Les ducs de B. et les boulevards de la chrétienté, pp. 239-256), les rapports avec les chrétiens d'Orient (Les ducs de B. et les chrétiens orientaux, pp. 257-271), l'accueil de réfugiés orientaux à la cour (Turcs, Maures et Grecs à la cour de B., pp. 273-290). Deux idées guide se reconnaissent dans l'ensemble du volume: la continuité, que J.P. réaffirme, de l'idée de croisade dans le royaume de France tout au long du Moyen Age (la dynastie de Bourgogne remplirait d'une certaine manière le 'vide' qui se crée dans la monarchie française entre Charles VI et Charles VIII) et le caractère particulier de la littérature bourguignonne dans ce domaine, qui s'avère un regard en arrière, vers des héros réels ou imaginaires du passé, plutôt que le reflet des événements contemporains, 
notamment la chute de Constantinople (1454), dont l'annonce bouleversa pourtant l'Europe occidentale.

3 On nous pardonnera de ne rendre compte que de la partie proprement littéraire de l'ouvrage. Après quelques observations d'ordre quantitatif sur la présence de la croisade dans la bibliothèque des Ducs, remarques nécessairement fondées sur les inventaires anciens et sur les études de Georges Doutrepont et de Georges Dogaer, J.P. analyse une série de textes diversement en rapport avec l'idée de croisade: des œuvres à caractère historique (la Belle Hélène de Constantinople de Jehan Wauquelin, Charles Martel en prose, les Croniques et Conquestes de Charlemagne de David Aubert), des 'biographies chevaleresques' (Cleriadus et Meliadice, Gillion de Trazegnies, Gilles de Chin, le Comte d'Artois, l'Histoire des Seigneurs de Gavre, les Trois fils de rois, Paris et Vienne, et celle qu'il définit 'littérature de propagande' (p. 227: les œuvres de Jean Germain, la Complainte de Grèce de Molinet, l'Epistre faitte en la contemplacion du saint voyage de Turquie, les textes réunis dans le ms. BnF fr. 11594, récemment édités par MarieThérèse Caron: cf. questi «studi», CXLV, 2005, pp. 134-135), pour conclure avec un manuscrit moins connu, contenant Les trois tapisseries de Turquie (BnF fr. 1193, commenté aux pp. 231-236). Tous ces ouvrages sont rapidement résumés, avec quelques citations des passages les plus significatifs dans la perspective adoptée. Le corpus aurait pu être élargi à d'autres romans connus et appréciés à la cour de Bourgogne: Baudouin de Flandres, la mise en prose du Chastelain de Coucy, Saladin surtout -troisième partie de Jehan d'Avennes, étonnamment exclu de la présentation de celui-ci. Par ailleurs, on ne saurait oublier qu'au $\mathrm{XV}^{\mathrm{e}}$ siècle la croisade constitue l'épisode culminant de la 'carrière' chevaleresque des protagonistes de bien d'autres romans, produits en dehors de la cour de Bourgogne: Jehan de Saintré, pour ne nommer que le plus célèbre, se doit de mener une campagne contre les payens en Prussie.

4 Le volume de J.P. comprend encore un riche dossier de Pièces justificatives (pp. 295-339), regroupant des documents inédits (documents d'archives surtout, mais aussi récits, traités, lettres diversement en rapport avec la croisade, couvrant toute la période considérée: 1396-1475), une bibliographie importante (pp. 341-353), et deux Indices (noms de lieu: pp. 355-364; noms de personne: pp. 365-389).

On nous permettra de signaler des travaux complémentaires, concernant soit d'autres documents (Monica Barsi, Constantinople à la cour de Philippe le Bon, in Sauver Byzance de la barbarie du monde, Milano, Cisalpino, 2004, pp. 131-195; ead., Le récit de Jacopo Tedaldi sur la prise de Constantinople: édition du ms. BNF, fr. 6487, in 'Pour acquerir honneur et pris'. Mélanges de Moyen Français offerts à Giuseppe Di Stefano, Montréal, CERES, 2004, pp. 195-208), soit plus spécialement la littérature bourguignonne (M.C.T., Cherchez la ville. Constantinople à la cour de Philippe le Bon 1419-1467, in Sauver Byzance de la barbarie du monde, Milano, Cisalpino, 2004, pp. 113-130; Ead., Le 'Cligés' en prose (1455), ou l'actualisation d'un ancien 'conte' en vers, in L'analisi linguistica e letteraria, VIII, 2000, pp. 329-342: cette dernière contribution pourrait répondre à la remarque de J.P., affirmant justement -p. 207- que la dimension historique et politique des œuvres littéraires est rarement prise en compte par les éditeurs de textes). 